\title{
Differences in subjective and objective evaluation of hyperhidrosis. Study among medical students
}

\author{
Łukasz Dobosz¹, Tomasz Stefaniak ${ }^{1}$, Joanna Halman², Anna Piekarska² \\ ${ }^{1}$ Department of General, Endocrine and Transplant Surgery, Faculty of Medicine, Medical University of Gdansk, Gdansk, Poland \\ 2Faculty of Medicine, Medical University of Gdansk, Gdansk, Poland \\ Adv Dermatol Allergol 2020; XXXVII (5): 700-704 \\ DOI: https://doi.org/10.5114/ada.2019.84227
}

\begin{abstract}
Introduction: Hyperhidrosis is a condition that significantly impairs patients' quality of life. Qualification for treatment in most cases is based only on subjective evaluation of symptoms without objective confirmation.

Aim: To evaluate the differences between subjective and objective evaluation of sweating among medical students. Material and methods: There were 179 participants involved in the study. Subjective evaluation of sweating was conducted using the Hyperhidrosis Disease Severity Scale and Numeric Rating Scale in 4 body areas: the face, palms, armpits and abdomino-lumbar area. Objective evaluation of sweating was performed using gravimetry. Results: The prevalence of hyperhidrosis in gravimetric measures was $1.12 \%$. In subjective evaluation hyperhidrosis (HDSS 3 or 4 ) was present in $11.17 \%$ of cases. There was no significant difference in subjective evaluation of hyperhidrosis between men and women (15\% vs. 9.24\%; $p=0.32)$. In gravimetry men showed a higher perspiration rate on the face (5.85 vs. 3.38; $p<0.05)$ and in the armpits (17.27 vs. 9.12; $p<0.05)$. Individuals with body mass index $\geq 25 \mathrm{~kg} / \mathrm{m}^{2}$ reported hyperhidrosis more often ( $28 \% \mathrm{vs.} 8.44 \%$; $p<0.05$ ); however, in gravimetric evaluation, beside the facial area, no significant differences in above-mentioned groups were observed.

Conclusions: There is a discrepancy between subjective and objective methods of evaluating sweating.
\end{abstract}

Key words: hyperhidrosis, sweating, gravimetry.

\section{Introduction}

Sweating is a physiological process controlled by the sympathetic nervous system that plays an important role in thermoregulation and metabolism in humans. Although sweat glands are distributed all over the human body, their density is the highest in the armpits, soles, palms and forehead [1]. Perspiration disorders may manifest as increased (hyperhidrosis) or decreased (hypohidrosis/anhidrosis) sweating, and both of these conditions may significantly impair the quality of life $[2,3]$. In hyperhidrosis $(\mathrm{HH})$ there are many possible methods of treatment, including oral medications (e.g. oxybutynin), topical agents (antiperspirants with aluminum chloride hexahydrate), injectable therapies with botulinum toxin, medical device therapies (e.g. iontophoresis), and surgical treatment (sympathectomy) [4]. Qualification for these procedures in most cases is based on subjective evaluation of symptoms without objective confirmation.

\section{Aim}

The primary aim of this study was to estimate the difference between subjective and objective evaluation of sweating among young adults from the Polish population. The secondary aims included the comparison of differences in perception of perspiration between males and females and the correlation between body mass index (BMI) and the effects of sweating self-evaluation and objective sweating measurement.

\section{Material and methods}

The sample included 179 participants (60 men and 119 women), Caucasian, aged 18 to 28 years (mean \pm SD: $22.15 \pm 1.92$ ), medical students, who agreed to participate in the study after getting to know the conditions and purpose of the study. Participants were excluded if they reported current medical therapy that might influence the rate of sweat production and history of previous

Address for correspondence: Lukasz Dobosz, Department of General, Endocrine and Transplant Surgery, Medical University of Gdansk, 17 Smoluchowskiego St, 80-255 Gdansk, Poland, phone: +48 583493 010, e-mail: lukaszdobosz@gumed.edu.pl Received: 30.11.2018, accepted: 1.03.2019. 
medical therapies due to $\mathrm{HH}$. Participants were asked to fill in the questionnaire concerning their age, sex, weight, height and subjective evaluation of sweating using the Hyperhidrosis Disease Severity Scale (HDSS) [5] (Table 1). Subsequently, they were asked to complete the Numeric Rating Scale (NRS) (1 - no sweating; 10 - maximal possible sweating) in 4 body areas: face, palms, armpits and abdomino-lumbar area. Subjects were considered to have $\mathrm{HH}$ if they chose 3 or 4 in the HDSS. Based on their scores, sweating was classified as mild (NRS: 1-3), moderate (NRS: 4-7), or severe (NRS: 8-10). Further, objective evaluation of sweating was performed in the same areas using gravimetry, described below. The study was conducted from September 2016 to June 2018. The study protocol was approved by the local ethical committee.

\section{Gravimetry}

After a 15-minute rest in a sitting position, the participants were invited into the air-conditioned measuring room with standardized temperature $\left(24-25^{\circ} \mathrm{C}\right)$ and humidity (15-17\%). A standard small cotton gauze pad was weighed on a precision scale. Then the pad was given to the participant, who was asked to carefully wipe their palms for $1 \mathrm{~min}$. The pad was weighed again and the difference was calculated. Subsequently, the procedure was repeated for the face, armpits and abdomino-lumbar area with separate cotton gauzes. Except for the palms, all measurements were taken in medical gloves to avoid summing up sweat from different areas. Thresholds for diagnosis of $\mathrm{HH}$ were quantified respectively as: $49 \mathrm{mg} /$ $\mathrm{min} / \mathrm{m}^{2}$ for the facial area, $46 \mathrm{mg} / \mathrm{min} / \mathrm{m}^{2}$ for the palms, $136 \mathrm{mg} / \mathrm{min} / \mathrm{m}^{2}$ for the armpits, and $50 \mathrm{mg} / \mathrm{min} / \mathrm{m}^{2}$ for the abdomino-lumbar area [6].

\section{Statistical analysis}

Statistical analysis was conducted using the computer software Statistica (Dell Inc. (2016). Dell Statistica (data analysis software system), version 13. software.dell. com) licensed to the Medical University of Gdansk, Poland. Descriptive statistics (range, mean, standard deviation, percentage distribution) were used. Student's t-test was used when comparing quantitative variables. The $\chi^{2}$ test was used when comparing qualitative variables. One-way ANOVA was used to analyze the differences between specific groups. Pearson correlation for parametric data and Spearman rank correlation for nonparametric data were used to analyze all correlations. The significance level was set at $p<0.05$.

\section{Results}

The prevalence of $\mathrm{HH}$ in gravimetric measurement was $1.12 \%(2 / 179)$. It was present in one man (1.67\%) and one woman (0.84\%). In both participants $\mathrm{HH}$ was noted only in one out of four areas measured: in the cranio-
Table 1. Hyperhidrosis Disease Severity Scale (HDSS) "How would you rate the severity of your hyperhidrosis?"

\begin{tabular}{|c|c|}
\hline Grade & \\
\hline 1 & $\begin{array}{c}\text { My sweating is never noticeable and never interferes } \\
\text { with my daily activities }\end{array}$ \\
\hline 2 & $\begin{array}{l}\text { My sweating is tolerable but sometimes interferes } \\
\text { with my daily activities }\end{array}$ \\
\hline 3 & $\begin{array}{l}\text { My sweating is barely tolerable and frequently } \\
\text { interferes with my daily activities }\end{array}$ \\
\hline 4 & $\begin{array}{l}\text { My sweating is intolerable and always interferes with } \\
\text { my daily activities }\end{array}$ \\
\hline
\end{tabular}

facial area and the abdomino-lumbar area, respectively. In subjective evaluation HH (HDSS 3 or 4) was noted in $11.17 \%$ (20/179) of participants and was significantly more frequent than in gravimetric measures. Both participants with $\mathrm{HH}$ diagnosed in the gravimetric test rated their level of sweating at 3 in the HDSS, and at 8 and 5 in the NRS, respectively. There was a weak positive correlation between NRS and gravimetric measures on the face $(r=0.25, p<0.05)$, palms $(r=0.25, p<0.05)$, in the abdomino-lumbar area $(r=0.19, p<0.05)$, and between HDSS and gravimetric measures on the face $(r=0.27$; $p<0.05)$.

In the overall subjective evaluation of $\mathrm{HH}$ (HDSS) there was no significant difference between men and women (15\% vs. 9.24\%; $p=0.32$ ). Nevertheless, men had higher subjective perception of sweating in the abdomino-lumbar area than women (2.65 vs. 1.87; $p<0.05)$, with no confirmation in gravimetry $\left(3.91 \mathrm{mg} / \mathrm{min} / \mathrm{m}^{2} \mathrm{vs}\right.$. $3.58 \mathrm{mg} / \mathrm{min} / \mathrm{m}^{2} ; p=0.80$ ). Other body areas (face, palms and armpits) did not show significant differences in subjective evaluation. In gravimetry men showed a higher perspiration rate than women in the facial area $(5.85 \mathrm{mg} /$ $\mathrm{min} / \mathrm{m}^{2}$ vs. $\left.3.38 \mathrm{mg} / \mathrm{min} / \mathrm{m}^{2} ; p<0.05\right)$ and in the armpits $\left(17.27 \mathrm{mg} / \mathrm{min} / \mathrm{m}^{2}\right.$ vs. $\left.9.12 \mathrm{mg} / \mathrm{min} / \mathrm{m}^{2} ; p<0.05\right)$. The results are presented in Table 2 .

The comparison of subjective and objective evaluation of sweating in particular body areas showed that participants who perceived their localized sweating as severe (NRS 8-10) had a significantly higher level of perspiration confirmed in gravimetry on the face and palms than those who assessed their sweating level as mild or moderate. These differences were not significant in the armpits or the abdomino-lumbar area. There was also no significant difference between participants who assessed their perspiration level as mild or moderate in all examined body areas (Figure 1).

Twenty-eight percent of participants with $\mathrm{BMI} \geq 25 \mathrm{~kg} / \mathrm{m}^{2}$ $(7 / 25)$ rated their overall sweating as severe in the HDSS and it was a result significantly higher than in the group with $\mathrm{BMI}<25 \mathrm{~kg} / \mathrm{m}^{2}(8.44 \%$; $p<0.05)$. In men there was no significant difference between groups (22.72\% vs. $10.53 \%$; $p=0.26)$, but there was a signifi- 
Table 2. Differences between men and women in subjective and objective evaluation of sweating (sub - subjective evaluation in NRS scale (1-10), grav - gravimetric evaluation [mg/min/m²], ALA - abdomino-lumbar area)

\begin{tabular}{lcccc}
\hline Parameter & Overall & Men $(n=60)$ & Women $(n=119)$ & $P$-value \\
\hline BMI $\left[\mathrm{kg} / \mathrm{m}^{2}\right]$ & $22.29 \pm 2.87$ & $24.31 \pm 3.21$ & $21.27 \pm 2.05$ & $<0.05$ \\
\hline Age [years] & $22.15 \pm 1.92$ & $22.15 \pm 2.13$ & $22.15 \pm 1.82$ & 0.99 \\
\hline HDSS $1 / 2$ & $159(88.83 \%)$ & $51(85 \%)$ & $108(90.76 \%)$ & 0.32 \\
\hline HDSS 3/4 & $20(11.17 \%)$ & $9(15 \%)$ & $11(9.24 \%)$ & 0.24 \\
\hline Sub face & $3.42 \pm 2.07$ & $3.68 \pm 2.24$ & $3.29 \pm 1.97$ & 0.16 \\
\hline Sub palms & $3.83 \pm 2.38$ & $4.18 \pm 2.68$ & $3.65 \pm 2.21$ & 0.91 \\
\hline Sub armpits & $5.22 \pm 2.12$ & $5.25 \pm 2.13$ & $5.21 \pm 2.13$ & $<0.05$ \\
\hline Sub ALA & $2.13 \pm 1.61$ & $2.65 \pm 1.93$ & $1.87 \pm 1.36$ & $<0.05$ \\
\hline Grav face & $4.25 \pm 7.03$ & $5.85 \pm 10.51$ & $3.38 \pm 3.87$ & 0.49 \\
\hline Grav palms & $5.07 \pm 4.13$ & $4.77 \pm 4.23$ & $5.22 \pm 4.09$ & $<0.05$ \\
\hline Grav armpits & $11.85 \pm 12.04$ & $17.27 \pm 14.93$ & $9.12 \pm 9.2$ & 0.8 \\
\hline Grav ALA & $3.66 \pm 9.34$ & $3.91 \pm 5.48$ & $3.54 \pm 10.80$ & \\
\hline
\end{tabular}
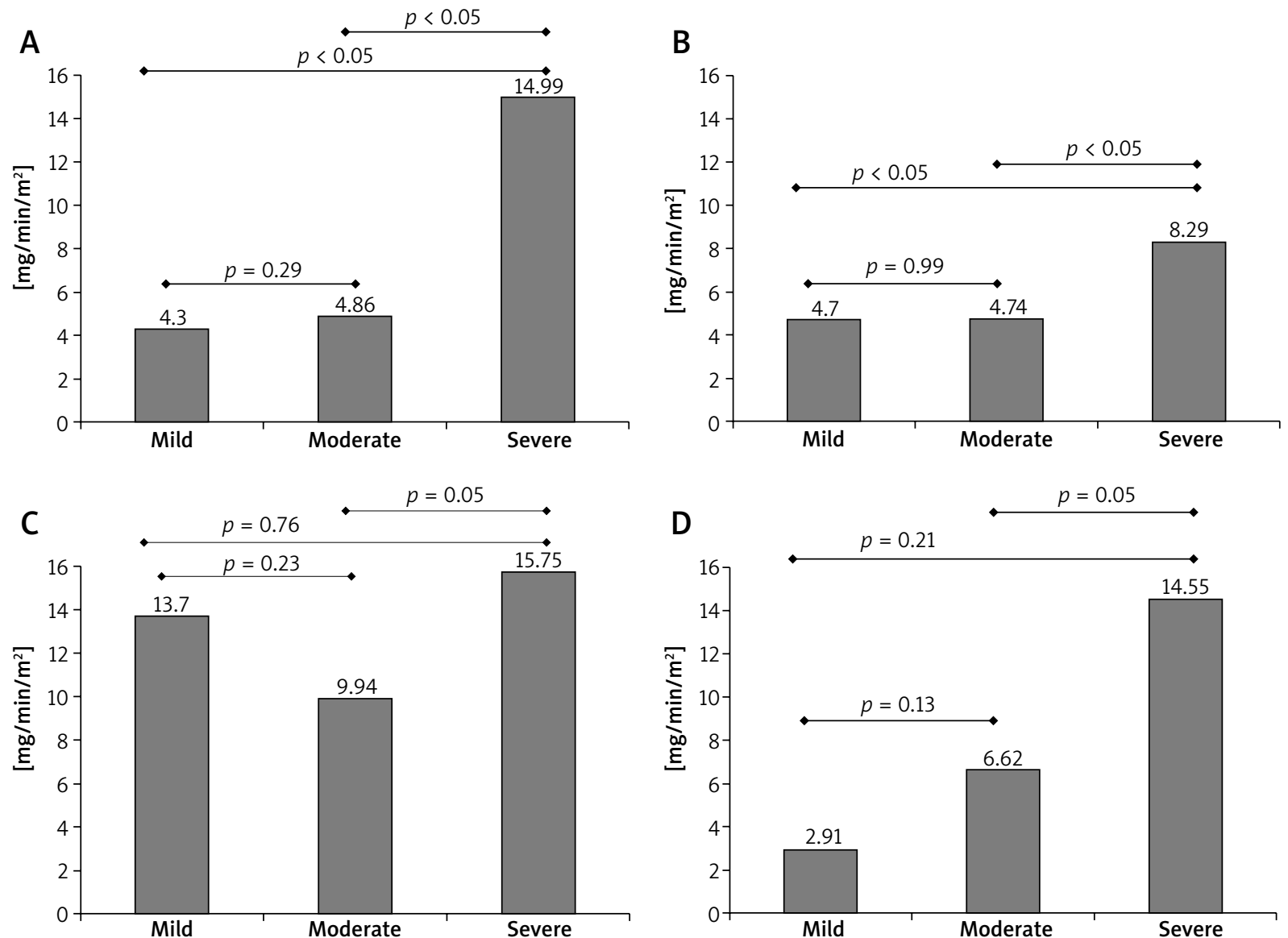

Figure 1. Association between subjective (NRS scale) and objective (gravimetry) evaluation of sweating in different body areas: $\mathbf{A}$ - face, $\mathbf{B}$ - palms, $\mathbf{C}$ - axillae, D - abdomino-lumbar area. The sweating level was classified as mild (NRS: 1-3), moderate (NRS: 4-7) or severe (NRS: 8-10) 
cant difference in women $(66.67 \%$ vs. $7.76 \% ; p<0.05)$. Participants with $\mathrm{BMI} \geq 25 \mathrm{~kg} / \mathrm{m}^{2}$ sweated more in the facial area (both subjectively -4.52 vs. 3.25; $p<0.05$ and objectively $-8.80 \mathrm{mg} / \mathrm{min} / \mathrm{m}^{2}$ vs. $3.47 \mathrm{mg} / \mathrm{min} / \mathrm{m}^{2}$; $p<0.05$, respectively). In other body areas there were no significant differences between the groups (Table 3).

\section{Discussion}

Population prevalence of $\mathrm{HH}$ is not precisely estimated and differs in various studies. Two large surveys from the United States showed that $\mathrm{HH}$ can be observed in $2.8 \%$ or $4.8 \%$ of the society $[7,8]$. In other countries $\mathrm{HH}$ had even higher prevalence: $16.3 \%$ in Germany, $13.95 \%$ in Japan, and $20.3 \%$ in Sweden [9-11]. Most of the abovementioned studies used the HDSS or other hyperhidrosis-specific questionnaires to evaluate the subjective level of sweating. In our study the prevalence of $\mathrm{HH}$ was also measured with the HDSS and was $11.17 \%$.

So far the literature does not include studies that assess the prevalence of $\mathrm{HH}$ using objective methods. When based on the reference values for gravimetric diagnosis of $\mathrm{HH}$, published by Stefaniak and Proczko [6], the incidence of $\mathrm{HH}$ in our study was only $1.12 \%$, which is significantly lower than in subjective measures. In subjective evaluation however, NRS seems to be a useful scale. Participants who assessed their sweating level as severe had significantly higher perspiration rates in all measured locations.

In most studies the incidence of $\mathrm{HH}$ is similar in both genders or slightly higher in men [9-12]. Nevertheless, women more often look for medical help with that condition [13]. In subjective evaluation using the HDSS our survey confirms the above-mentioned results - men reported $\mathrm{HH}$ more often than women, but the difference had no statistical significance. In objective evaluation the difference in severity of sweating was determined by the body area. It showed that men had increased perspiration on the face and armpits, whereas sweating on palms and in the abdomino-lumbar area remained at the same level in both sexes.

It is hypothesized that overweight and obese people present more severe sweating than the general population. Individuals with a thick layer of fat in the subcutaneous tissue have greater difficulty in losing heat through convection and irradiation, and so it seems that evaporation is a natural compensatory mechanism [14]. Liu et al. reported that $\mathrm{BMI}$ does not play an important role in the prevalence of primary $\mathrm{HH}$, although those who had BMI $>24.9 \mathrm{~kg} / \mathrm{m}^{2}$ were more than twice as likely to develop late-onset $\mathrm{HH}$ than people who were not overweight or obese [15]. Increased $\mathrm{HH}$ in overweight and obese individuals was also observed by Westphal et al. [16]. In their study on 293 medical students, HH was diagnosed using the HDSS. In our study the results were similar to those presented by Westphal. In subjective evaluation over-

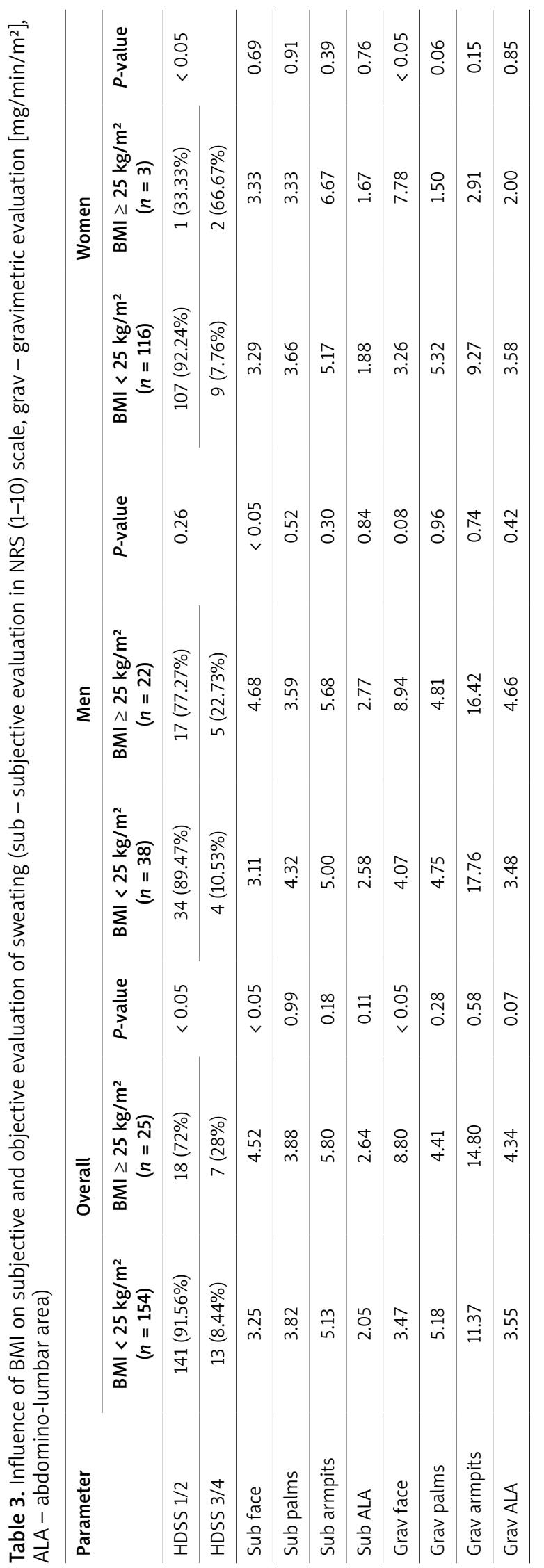


weight and obese individuals had a significantly higher rate of $\mathrm{HH}$. However, in gravimetric measures, a significant difference was only noted in the facial area and the perspiration remained at the similar level in other body areas.

The present study has several limitations. In our study the participants' age ranged from 18 to 28 years. Thus, the prevalence of $\mathrm{HH}$ may be lower than in the general population and it may be speculated that most cases of excessive sweating were associated with primary $\mathrm{HH}$; nevertheless, to reflect the proper prevalence of $\mathrm{HH}$ in the general population both younger and older participants should be included in the study, and for proper diagnosis Hornberger's criteria should be applied [17]. The second limitation is that gravimetry was performed at one time point, whereas the subjective measures took into account 24-hour real life of the participants. This may potentially lead to inaccurate results, as the perspiration intensity may change in time during the day. However, according to the authors' observations, the results of gravimetry are very comparable and stable over time in controlled evaluation conditions (temperature and humidity) [18].

\section{Conclusions}

We found that there is a discrepancy between subjective and objective method of evaluating sweating. Men and women have similar incidence of $\mathrm{HH}$ in subjective evaluation, although in objective measures men have increased perspiration intensity on the face and in the armpits. The incidence of $\mathrm{HH}$ in overweight and obese individuals is higher in subjective evaluation, but beside the facial area the level of perspiration is similar to that observed in the general population.

Both non-invasive and invasive treatment of primary $\mathrm{HH}$ may have its complications and serious side effects, such as compensatory sweating after thoracic sympathectomy. Therefore, in the opinion of the authors, it is possible to use subjective methods more as a screening test, but the choice for the treatment must be based on objective evaluation of sweating.

\section{Conflict of interest}

The authors declare no conflict of interest.

\section{References}

1. Peng Y, Cui X, Liu Y, et al. Systematic review focusing on the excretion and protection roles of sweat in the skin. Dermatology 2014; 228: 115-20.

2. Munetsugu T, Fujimoto T, Satoh T, et al. Evaluation of the correlation between severity of acquired idiopathic generalized anhidrosis and quality of life scores. J Dermatol 2017; 44: 747-52.
3. de Campos JRM, da Fonseca HVS, Wolosker N. Quality of life changes following surgery for hyperhidrosis. Thorac Surg Clin 2016; 26: 435-43.

4. Grabell DA, Hebert AA. Current and emerging medical therapies for primary hyperhidrosis. Dermatol Ther (Heidelb) 2017; 7: 25-36.

5. Hamm H. Impact of hyperhidrosis on quality of life and its assessment. Dermatol Clin 2014; 32: 467-76.

6. Stefaniak TJ, Proczko M. Gravimetry in sweating assessment in primary hyperhidrosis and healthy individuals. Clin Auton Res 2013; 23: 197-200.

7. Strutton DR, Kowalski JW, Glaser DA, Stang PE. US prevalence of hyperhidrosis and impact on individuals with axillary hyperhidrosis: results from a national survey. J Am Acad Dermatol 2004; 51: 241-8.

8. Doolittle J, Walker P, Mills T, Thurston J. Hyperhidrosis: an update on prevalence and severity in the United States. Arch Dermatol Res 2016; 308: 743-9.

9. Augustin M, Radtke MA, Herberger K, et al. Prevalence and disease burden of hyperhidrosis in the adult population. Dermatology 2013; 227: 10-3.

10. Fujimoto T, Kawahara K, Yokozeki H. Epidemiological study and considerations of primary focal hyperhidrosis in Japan: from questionnaire analysis. J. Dermatol 2013; 40: 886-90.

11. Shayesteh A, Janlert U, Brulin C, et al. Prevalence and characteristics of hyperhidrosis in Sweden: a cross-sectional study in the general population. Dermatology 2016; 232: 586-91.

12. Moraites E, Vaughn OA, Hill S. Incidence and prevalence of hyperhidrosis. Dermatol Clin 2014; 32: 457-65.

13. Ricchetti-Masterson K, Symons JM, Aldridge M, et al. Epidemiology of hyperhidrosis in 2 population-based health care databases. J Am Acad Dermatol 2018; 78: 358-62.

14. de Campos JR, Wolosker N, Takeda FR, et al. The body mass index and level of resection: predictive factors for compensatory sweating after sympathectomy. Clin Auton Res 2005; 15: 116-20.

15. Liu Y, Bahar R, Kalia S, et al. Hyperhidrosis prevalence and demographical characteristics in dermatology outpatients in Shanghai and Vancouver. PLoS One 2016; 11: e0153719.

16. Westphal FL, de Carvalho MA, Lima LC, et al. Prevalence of hyperhidrosis among medical students. Rev Col Bras Cir 2011; 38: 392-7.

17. Hornberger J, Grimes K, Naumann M, et al. Recognition, diagnosis, and treatment of primary focal hyperhidrosis. J Am Acad Dermatol 2004; 51: 274-86.

18. Stefaniak T, Tomaszewski KA, Proczko-Markuszewska M, et al. Is subjective hyperhidrosis assessment sufficient enough? prevalence of hyperhidrosis among young Polish adults. J Dermatol 2013; 40: 819-23. 